\title{
Undercutting method selection at Cadia East PC2-3 extension
}

\author{
C Orrego Newcrest Mining Limited, Australia
}

R Lowther Newcrest Mining Limited, Australia

G Newcombe Newcrest Mining Limited, Australia

\begin{abstract}
The PC2-3 extension is set to be the first expansion of a previously established panel cave at Cadia East, which presents a unique boundary condition for the cave establishment and initiation. The choice of the undercutting method and the subsequent assessment of personnel exposure relating to seismic hazard was investigated through a comparative numerical modelling assessment of both the advanced and post undercut methods for the Cadia East PC2-3 extension using FLAC3D. This paper details the numerical modelling approach and interpretation of the results between the two methods spanning initial development, and undercutting. The results show a comparison of the stress abutment formation within the operating levels during cave establishment for each method coupled with a quantitative personnel exposure analysis to determine which method had the least amount of exposure of personnel working within the stress abutments. The results demonstrated that while each method had varying levels of exposure within specific areas, the overall personnel exposure is less for the post undercutting method. This finding, complemented with positive business outcomes and the implementation of safety controls including dynamic ground support, pre-conditioning, and caving rules, inclined the decision towards this method.
\end{abstract}

\section{Introduction}

This paper describes a process that compared the post undercut method to the advanced undercut method to determine which one was the safest to implement for the Cadia East Panel Cave 2 Stage 3 expansion. The process used a comparative numerical modelling approach to determine the spatial extent of the stress abutments within the operating levels for each method, and then a quantitative risk-based approach to determine the level of personnel exposure for the various activities that are to occur within the stress abutments for each method. The aim of this exercise was to determine which undercutting strategy produces the least personnel exposure during cave establishment, which was the key mandate for choosing which method would be employed for Panel Cave 2 Stage 3.

The Cadia East operation is located within the Newcrest owned Cadia province in Central-West New South Wales, approximately $25 \mathrm{~km}$ south-west of the city of Orange. The mine consists of two fully commissioned panel cave operations, Cadia East Panel Cave 1 (CE PC1) and Cadia East Panel Cave 2 (CE PC2) which are set at an approximate depth of 1,200 $\mathrm{m}$ and 1,400 $\mathrm{m}$ respectively. The combined operations achieve an annual production output of $30 \mathrm{Mt}$.

CE PC1 was successfully executed as a high-lift post undercut without the occurrence of major geotechnical disruptions, as described by Lett (2016); while CE PC2 was initially executed as a post undercut but transitioned to an advanced undercut after a pillar burst in February 2015 on the extraction level during undercutting. It was thought that transitioning CE PC2 to an advanced undercut would eliminate the risk of personnel being exposed to seismic events within the extraction level by removing the need for activities to occur within the stress abutments generated by the undercutting process. 
Cadia East Panel Cave 2 Stage 3 (CE PC2-3) is the next planned expansion of the Cadia East operation which will extend the footprint further to the east of the existing CE PC2. The CE PC2-3 extraction level, however, will be set approximately $25 \mathrm{~m}$ deeper than the CE PC2 extraction level. Figure 1 shows a plan view of the CE PC2-3 extraction level footprint in relation to the existing CE PC1 and CE PC2 extraction level footprints.

The alignment of the CE PC1 and CE PC2 extraction levels drives (EXTs) is $25^{\circ} \mathrm{N}-\mathrm{N}-\mathrm{W}$ with the crusher chambers located on the southern side of the orebody. The CE PC2-3 EXT drives, by contrast, are aligned $65^{\circ} \mathrm{E}-\mathrm{N}-\mathrm{E}$ to allow the CE PC2-3 crusher chamber to be located to the east of the orebody where the final state stress abutment and expected seismic hazard is relatively low (Orrego 2018). Figure 1 also displays the EXT and Drawpoint drive orientations of the three panels and the location of the CE PC2-3 crusher on the eastern side of the footprint.

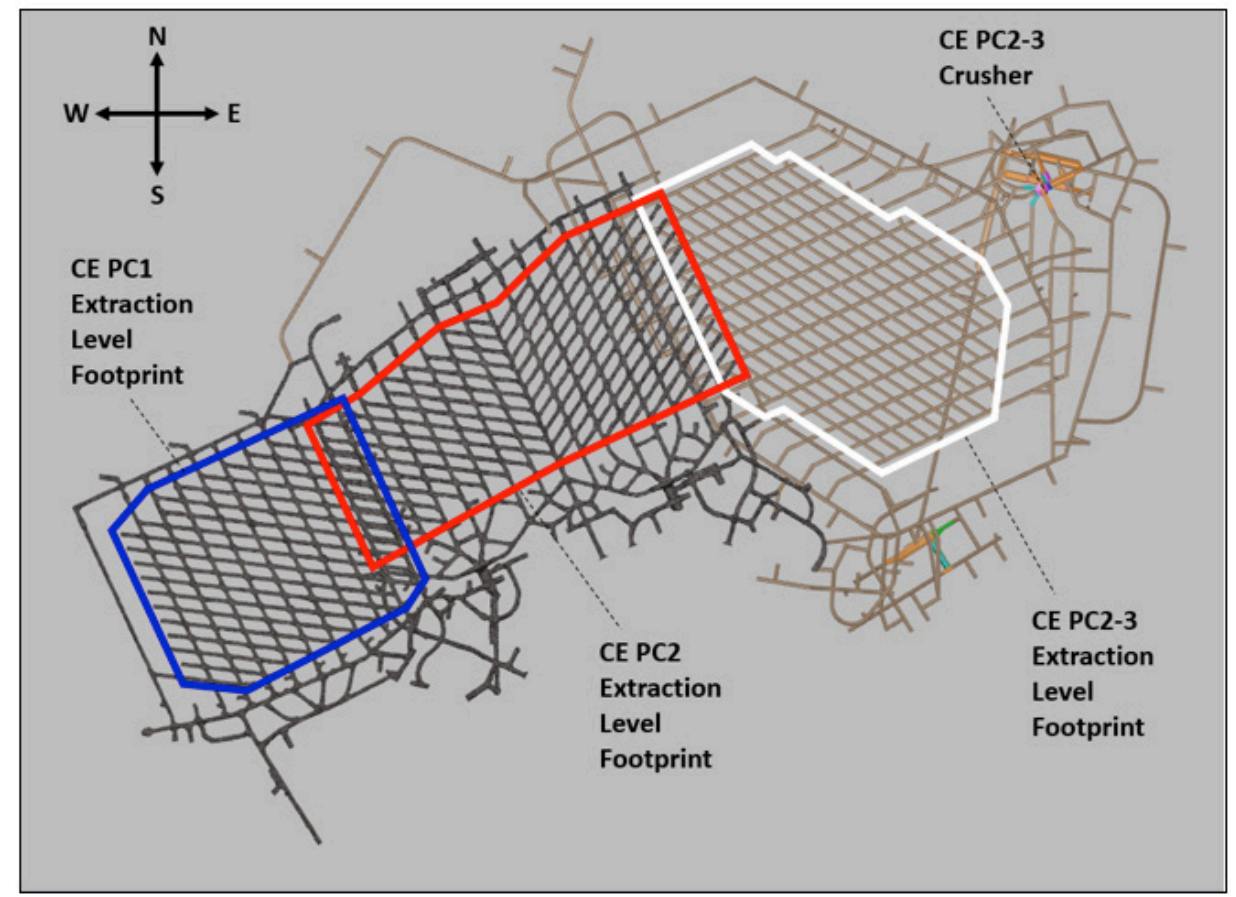

Figure 1 Plan view of the CE PC1, CE PC2, and CE PC2-3 extraction levels showing the E-N-E/W-S-W alignment of the CE PC2-3 extraction drives

\section{Geotechnical setting}

\section{$2.1 \quad$ Structure}

CE PC2-3 is located at the most easterly extent of the strike-slip fault stepover that hosts the Cadia East orebody. The dominant structure affecting the panel is the Carb 5 Fault, a northeast-striking late fault that thrusts and rotates the orebody approximately 15 degrees clockwise from footwall to hanging wall. This fault consists of one to numerous slip planes with a bleached alteration selvedge that is typically 2-4 $\mathrm{m}$ wide. P-wave analysis on core demonstrates this to be a softer zone compared to the surrounding rock. Carb 5 fault is strongly brecciated in the east of the CE PC2-3 footprint.

The CE PC2-3 footprint has greater north-south dimensions compared to CE PC2 as the Carb faults rotate the tapered orebody at its eastern limit over the southern half of the footprint. At the undercut level, the stepover-bounding P1 Fault, which is roughly parallel and contiguous with the Carb 5 Fault, marks a fundamental change to the dominant structural fabric. North of P1 is inside the fault stepover with a dominant structural fabric that strikes southwest-northeast. South of P1 is outside the fault stepover and the dominant structural fabric is northwest-southeast. These fabrics preclude cave initiation on an undercut front perpendicular to the extraction drives as this is parallel to the major structures for the northern two-thirds of the footprint. 


\section{$2.2 \quad$ Lithology}

The main host rock type comprising the CE PC2-3 footprint consists of volcaniclastic sediments with monzonite and porphyry intrusions present. The monzonite intrusive is discontinuous and occurs as thin fingers and small isolated masses in the western side of CE PC2-3. Porphyry dykes are fewer than at higher levels but extend through the footprint. As these exploit pre-existing fractures for emplacement, they are typically oriented parallel to the dominant structural fabric, i.e. northeast in the north of CE PC23 , southeast in the south of CE PC2-3. An exception to this is the southern fringe of the footprint where there is the possibility of northeast-oriented dykes that have emplaced in tensional fractures formed during fault stepover formation. These porphyry intrusions are hard to very hard and stiffer than the host sediments, creating a rheological contrast that can increase the risk of rockburst during the development and undercutting phase.

Figure 2 displays a horizontal cross section +/- 50 m vertical of the CE PC2-3 extraction level showing the location of the Carb 5 and P1 faults, the monzonite and porphyry intrusions, and the location of other mine scale structures intersecting the CE PC2-3 footprint.

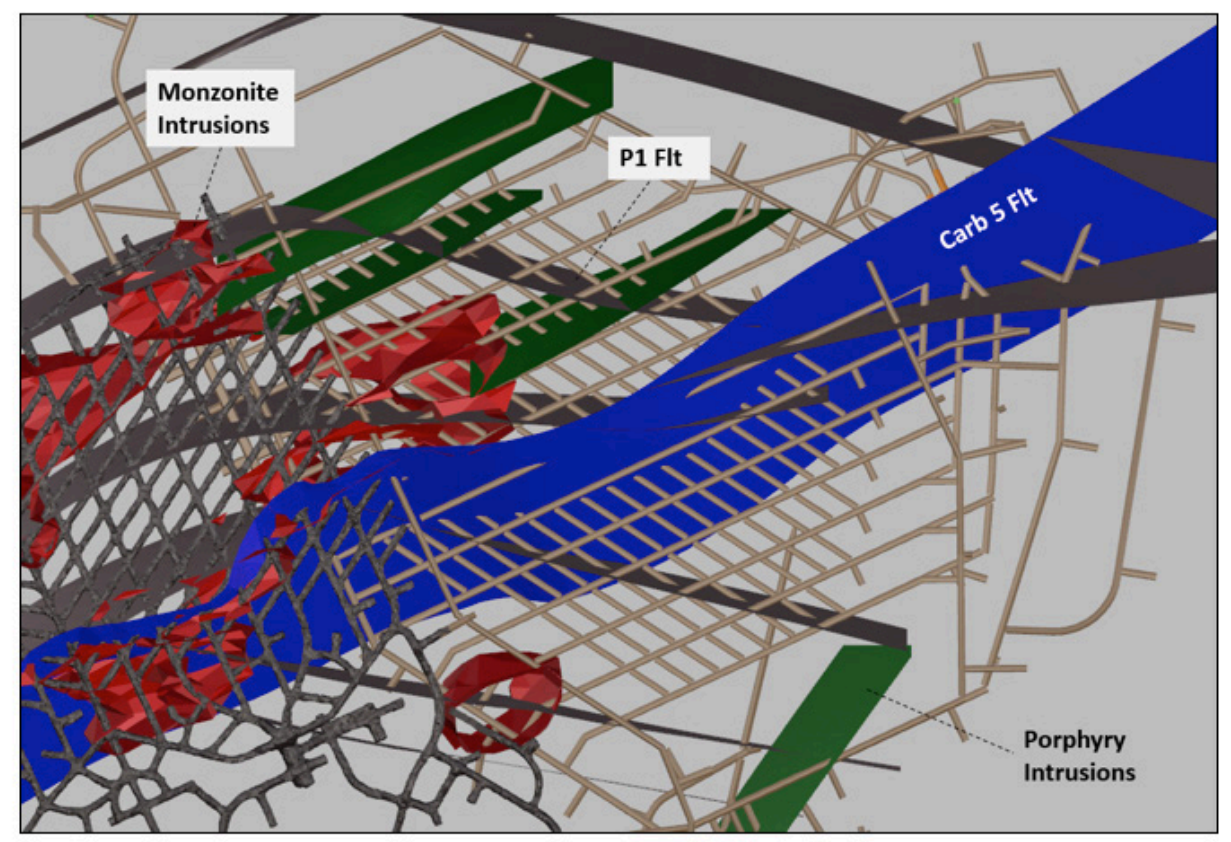

Figure 2 A section +/- 50 m vertical of the CE PC2-3 extraction level showing the location of the Carb 5 and P1 faults, the monzonite and porphyry intrusions, and the location of other mine scale structures intersecting the CE PC2-3 footprint

\subsection{Geotechnical domains}

The main geotechnical domains relevant to the CE PC2-3 expansion are listed in Table 1. The Silurian and capping porphyries are located within $500 \mathrm{~m}$ of the surface and are relevant to cave propagation and subsidence, while the undercut and extraction levels are set in the volcaniclastic and monzonite domains. The values listed in Table 1 are average envelopes derived from laboratory testing of intact samples, core logging and numerical modelling back analysis. 
Table 1 Rock mass properties

\begin{tabular}{|c|c|c|c|c|c|}
\hline Geotechnical Domain & $\sigma_{\mathbf{c i}}(\mathbf{M P a})$ & $\mathbf{m i}$ & $\mathbf{G S I}$ & $\mathbf{E i}(\mathbf{G P a})$ & Reference \\
\hline Silurian & 50 & 12.4 & 30 & 25 & Itasca (2017a) \\
\hline Upper Capping Porphyry & 80 & 20 & 43 & 30 & Itasca (2017a) \\
\hline Lower Capping Porphyry & 168 & 25 & 49 & 45 & Itasca (2017a) \\
\hline Monzonite & 157 & 26.8 & 59 & 70 & Noma (2018) \\
\hline Volcaniclastics & 156 & 18 & 47 & 40 & Itasca (2017a) \\
\hline
\end{tabular}

\subsection{Stress conditions}

The pre-mining stress regime is detailed in Table 2. This stress regime was derived by Lee (2012) and encompasses a weighted average of the stress measurement data set collected at Cadia East which spans 2008 to 2012.

Table 2 Cadia East pre-mining stress regime (Lee 2012)

\begin{tabular}{|c|c|c|c|}
\hline $\begin{array}{c}\text { Principal } \\
\text { Stress }\end{array}$ & $\begin{array}{c}\text { Regime Magnitude Criteria } \\
(\mathbf{M P a}) \text {, depth in }(\mathbf{m})\end{array}$ & Dip & Bearing \\
\hline$\sigma_{1}$ & $5.0+(0.0479 \times$ depth $)$ & $00^{\circ}$ & $074^{\circ}$ \\
\hline$\sigma_{2}$ & $0.0+(0.0344 \times$ depth $)$ & $00^{\circ}$ & $164^{\circ}$ \\
\hline$\sigma_{3}$ & $0.0+(0.0297 \times$ depth $)$ & $90^{\circ}$ & $074^{\circ}$ \\
\hline
\end{tabular}

\section{$3 \quad$ Undercutting methods alternatives}

Two undercutting methods were assessed as part of the CE PC2-3 feasibility study. These included an advanced undercut (Big W cut) in which the drawpoint and drawbell development lagged the undercut, and a high-lift post undercut in which the established drawbells led the undercut front. Both options incorporated an El Teniente style layout where the extraction drives (EXTs) were spaced at $32 \mathrm{~m}$ and the drawpoint drives were spaced at $20 \mathrm{~m}$. The undercut level drill drives (UDDs) were spaced at $32 \mathrm{~m}$. The key geometrical differences between the two methods was in the apex pillar geometry and the location of the UDDs in relation to the major apex pillars.

\subsection{Undercut method geometries}

The advanced undercut option incorporated a major apex pillar $41.6 \mathrm{~m}$ in height. The undercut level was located $20.1 \mathrm{~m}$ vertically above the extraction level and the UDDs were located directly above the centre of the drawbells resulting in drawbells $15.5 \mathrm{~m}$ in height. This methodology also incorporated an apex level to ensure that no remnant pillars could be left above the major apex pillars, resulting in point loading and a risk of collapse of the apex pillars. This risk of point loading is specific to the advanced undercut option because of the reliance of long-hole drilling to effectively break out the in-situ rock to form the top of the major apex pillars. The presence of the apex level diminishes this risk.

The post undercut option incorporated a major apex pillar $26 \mathrm{~m}$ in height. The undercut level was located $26 \mathrm{~m}$ vertically above the extraction level with the UDDs located directly above the crown of the major apex pillar. This layout ensures that the crown of the major apex pillar is formed without relying on drilling and blasting or the need for an apex level and hence removes the risk of remnant pillar formation leading to pillar collapse. The resulting drawbells are $19.4 \mathrm{~m}$ in height upon establishment and become $13.4 \mathrm{~m}$ in height when the undercut front passes overhead. Figure 3 displays the comparison of the pillar geometry between the advanced undercut and post undercut option. 


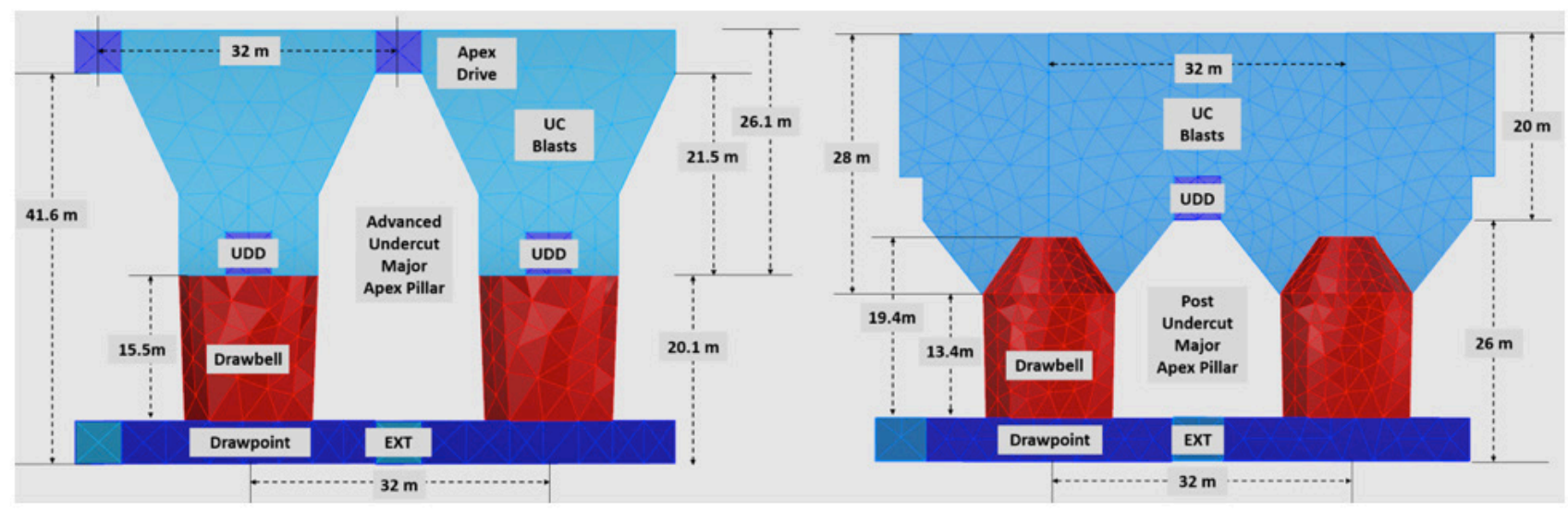

Figure 3 Advanced undercut option pillar geometry showing the location and dimensions of the extraction level, undercut level, apex level, and drawbells

\subsection{Undercut method sequences}

The advanced undercut sequence involved the drawpoint and drawbell establishment lagging the undercut front by $60 \mathrm{~m}$. All the EXT drives, however, were advanced ahead of the undercut front. The post undercut option sequence involved all the drawpoint drives being established prior to undercutting, while one full drawbell was established ahead of the undercut front. In order to increase the size of the drawpoint pillars, to reduce pillar stresses during undercutting, every second EXT drive was advanced ahead of the undercut front, while the alternate EXT drives lagged the undercut front by $40 \mathrm{~m}$, in accordance with the Newcrest Caving rules described by Cuello \& Newcombe (2018). Figure 4 displays the comparison between the advanced and post undercut mining sequences showing the position of the drawpoint drives and drawbell establishment in relation to the undercutting front.

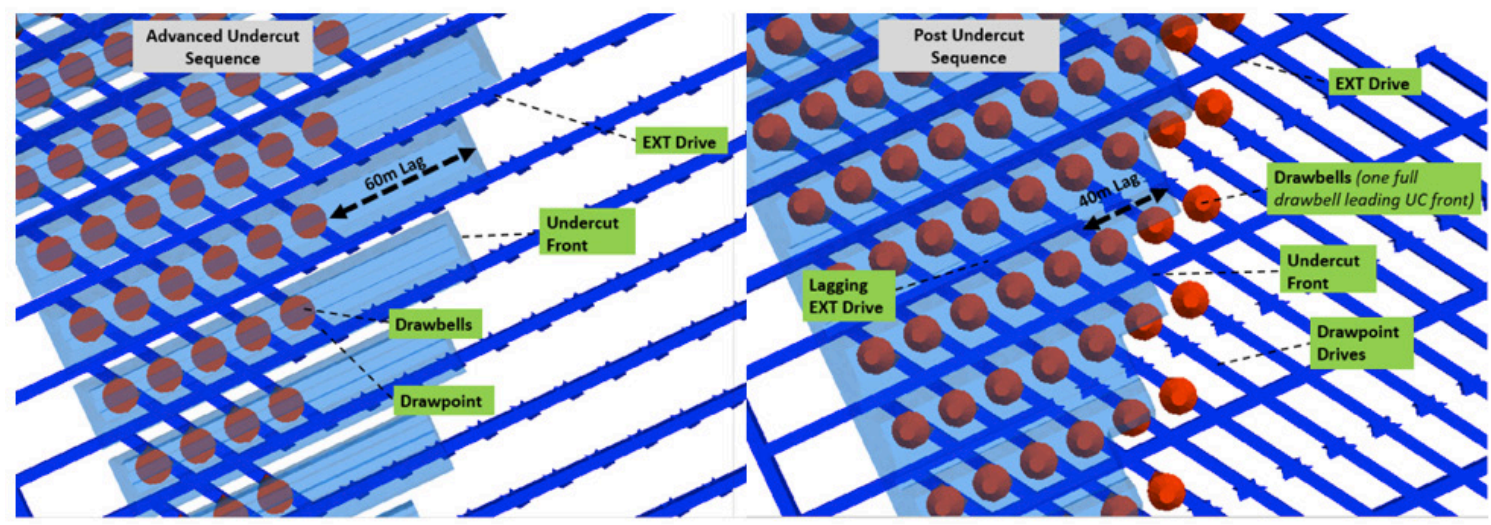

Figure 4 Post undercut option pillar geometry showing the location and dimensions of the extraction level, undercut level, and drawbells

Regardless of the undercutting method, the CE PC2-3 undercut sequence is to commence from the northeastern corner of the existing CE PC2 cave zone and progress in a south-eastern direction. The main criterion for this strategy is safety driven, as commencing the undercut from an existing cave eliminates the possibility of a pendant of intact rock forming between the existing CE PC2 and CE PC2-3 cave zones leading to the potential for large seismic events and orebody sterilization. The secondary criterion is economically driven, as commencing the undercut from the north-eastern corner of the CE PC2 cave allows higher grade ore to be accessed first. Finally, the overall stress field and major structural features were also taken into account. Figure 5 displays the CE PC2-3 undercut progression sequence showing the undercut commencing from the north-eastern corner of the existing CE PC2 cave and progressing in a south-eastern direction. The post undercut configuration is shown in this figure as an example. 


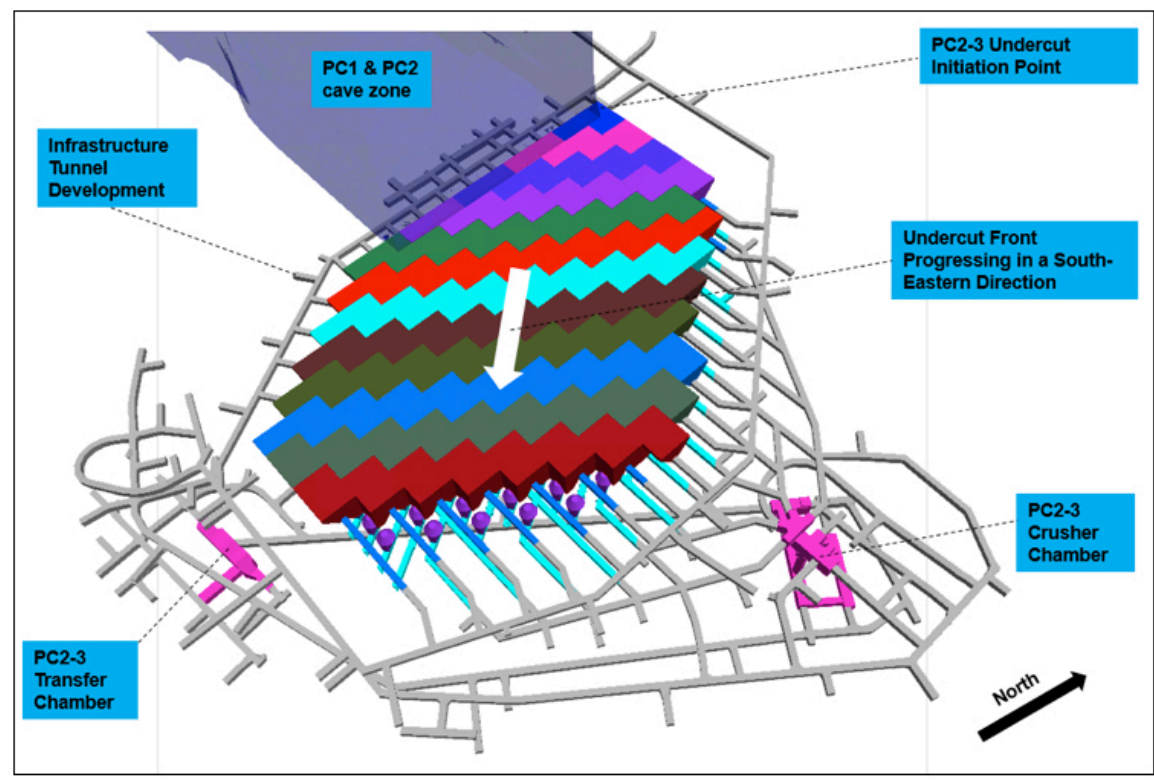

Figure 5 PC2-3 undercut progression sequence showing the undercut commencing from the north-eastern corner of the existing CE PC2 cave and progressing in a south-eastern direction. Post undercut configuration is shown

\section{$4 \quad$ Numerical modelling for geotechnical hazard assessment}

In order to perform the comparative assessment between the two undercutting methods, a numerical model of each was performed explicitly excavating drives, drawbells and undercut firings following the overall mining sequence. The models were developed using FLAC3D (Itasca 2017b) and incorporated a Hoek-Brown strain-softening constitutive model. This approach allowed for the implementation of a post-peak behaviour including tension weakening, cohesion weakening and frictional strengthening. The estimation of the rock mass Young's modulus was implemented using the relationships described in Hoek \& Diederichs (2006). In order to compensate for mesh-dependency in strain-softening models, the following equation was used (Lorig \& Pierce 2000) to implement the critical plastic shear strain required to transition from peak to residual strength:

$$
\varepsilon_{\text {crit }}^{S}=\frac{12.5-0.125 G S I}{100 Z_{w}}
$$

Where

$Z_{W}$ is the zone or element size

The FLAC3D models were interpreted to assess the key differences between the post and advanced undercutting methods for CE PC2-3. This assessment was based on the linear extent per drive unit above a maximum principal stress magnitude (Sigma 1) threshold, for each method during both the level establishment and undercutting phase. Only the linear extents where personnel were exposed outside the protection of a Falling Objects Protection Systems (FOPS) cabin were considered. The Sigma 1 stress abutment, which represents the maximum tangential stress induced by the excavations, is an applicable variable for assessing the two methods as it is directly proportional to strain-bursting proneness in massive-brittle rock masses as Cadia East. Additionally, this parameter was selected for its simplicity to communicate and discuss with the various stakeholders. As described by Kaiser et al. (2019) failures modes with localised spalling or stress-fracturing are observed once the stress level $S L=\sigma_{\max } / U C S$ exceeds 0.3 to $0.5\left(\mathrm{M}_{12}\right.$ and $\left.\mathrm{M}_{13}\right)$; where $\sigma_{\max }$ corresponds to the maximum tangential stress near the wall of the excavation. 
When assessing the Sigma 1 stress abutments during level establishment, a scale of 0 to $100 \mathrm{MPa}$ and an $80 \mathrm{MPa}$ threshold contour was used to assess the spatial extents of the stress abutment; which roughly corresponds to Sigma 1 over UCS of 0.5 . However, during the undercutting process, this ratio was uplifted to approximately 0.6 considering that in this stage the dynamic ground support shall be fully installed and functional; therefore, a scale of 0 to $110 \mathrm{MPa}$ and a $90 \mathrm{MPa}$ threshold contour was used.

For the level establishment phase, Figure 6 displays the quantification of linear extension per drive unit over the predefined threshold for the different levels of both methods while Figure 7 presents a sideby-side comparison of the linear exposure per drive unit for the extraction levels of each method. Note, because the post method only develops every second extraction drive prior to undercutting, the linear extent of the threshold contour in the extraction drives is halved to achieve a fair comparison between the two methods. Similarly, only the drawpoint drives associated with that specific extraction drive are counted when assessing the post method.

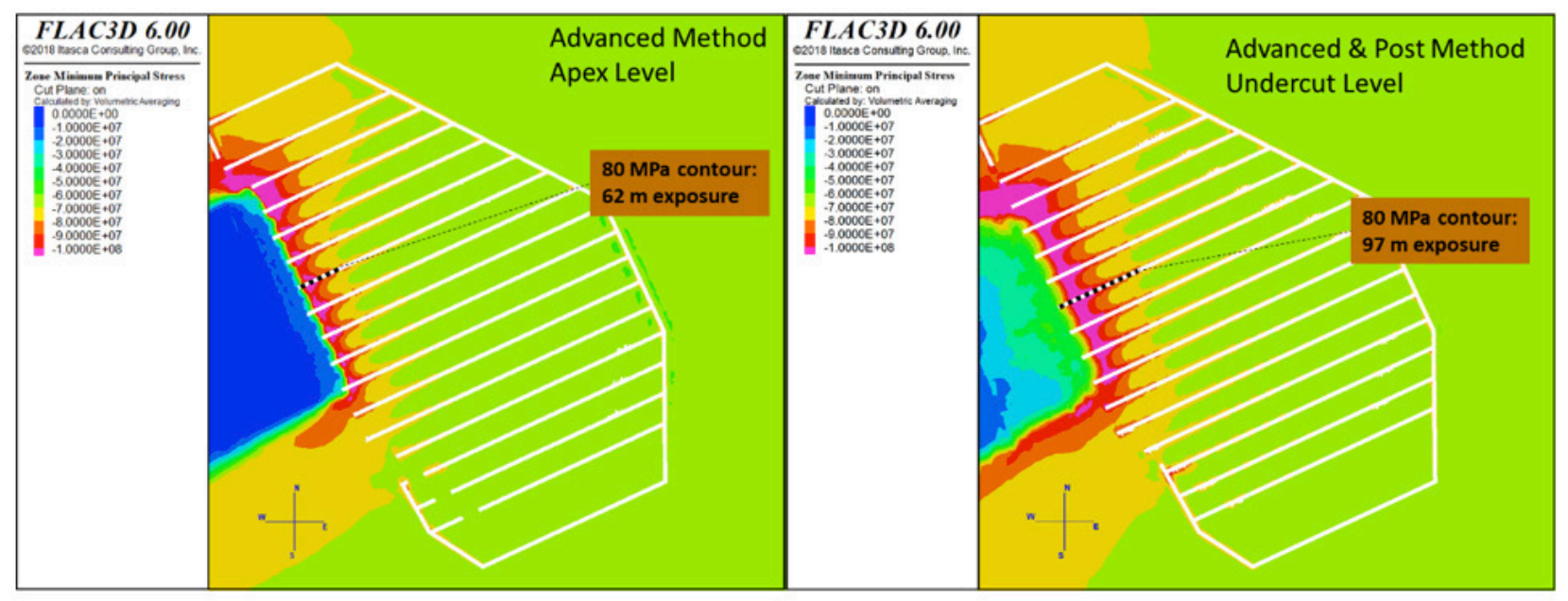

Figure 6 Apex level stress abutment for the advanced method and undercut level stress abutment for both methods during level establishment

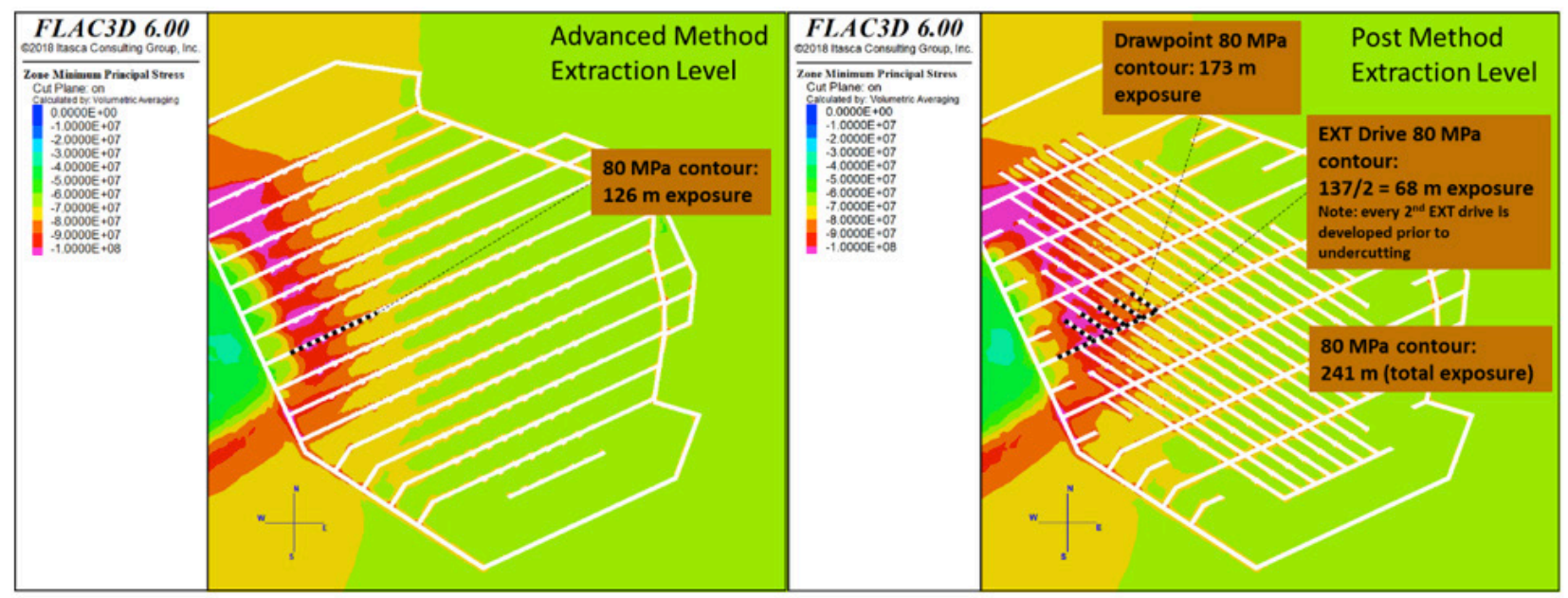

Figure 7 Extraction level stress abutments for both methods during level establishment

Similarly, for the undercutting phase Figure 8 displays the quantification of the linear extent per drive unit over the predefined threshold for the apex level for the advanced method while Figure 9 and Figure 10 show a side-by-side comparison of the linear extent per drive unit for the undercut level and extraction levels for both methods respectively. 


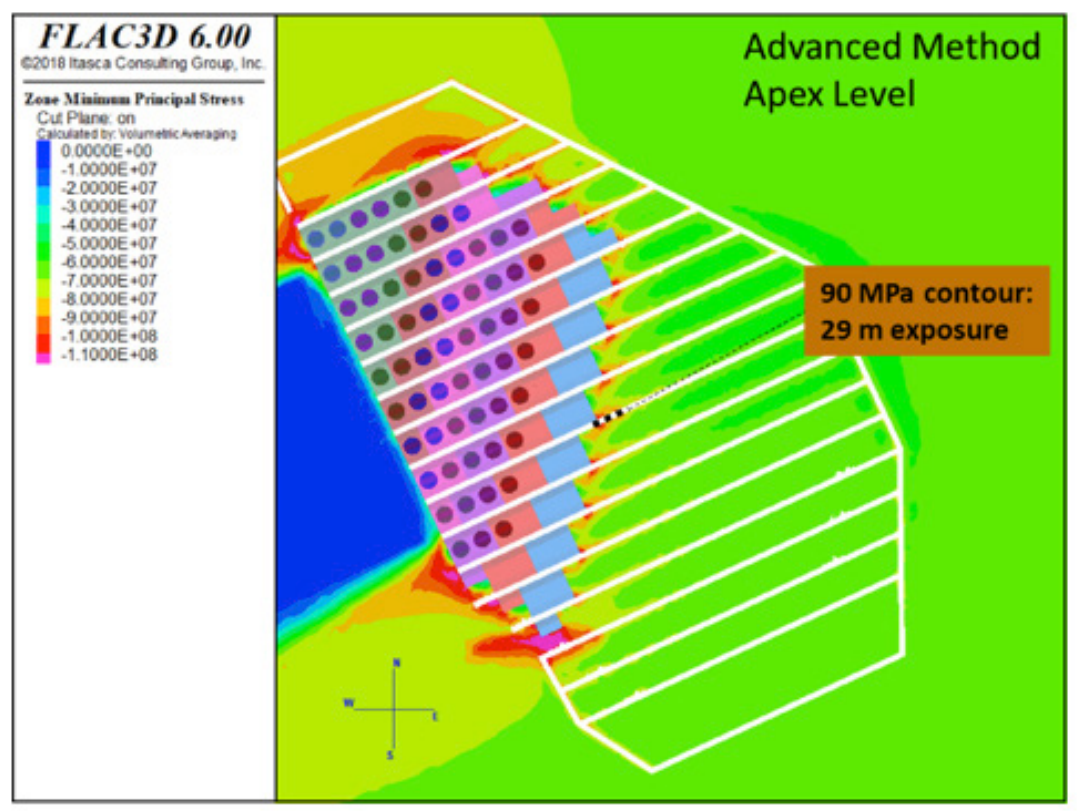

Figure 8 Stress abutment within the advanced method apex level during undercutting

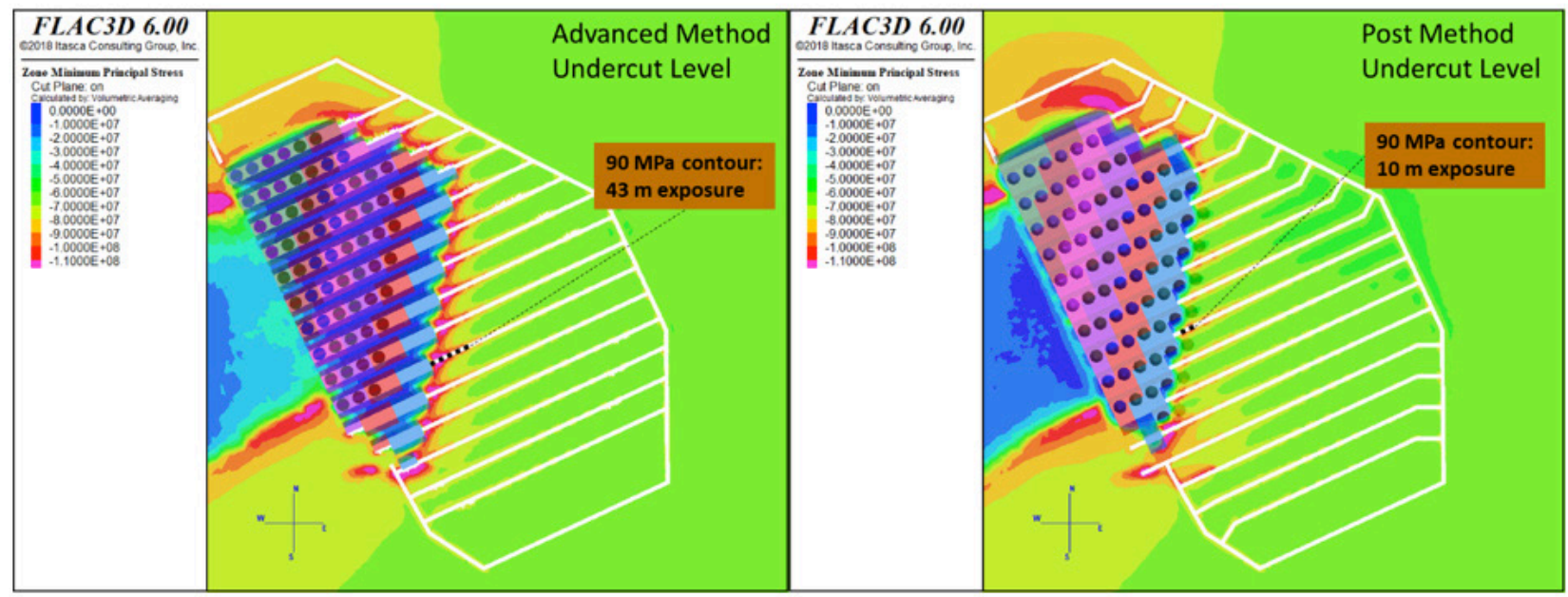

Figure 9 Stress abutments within the undercut levels for both methods during undercutting

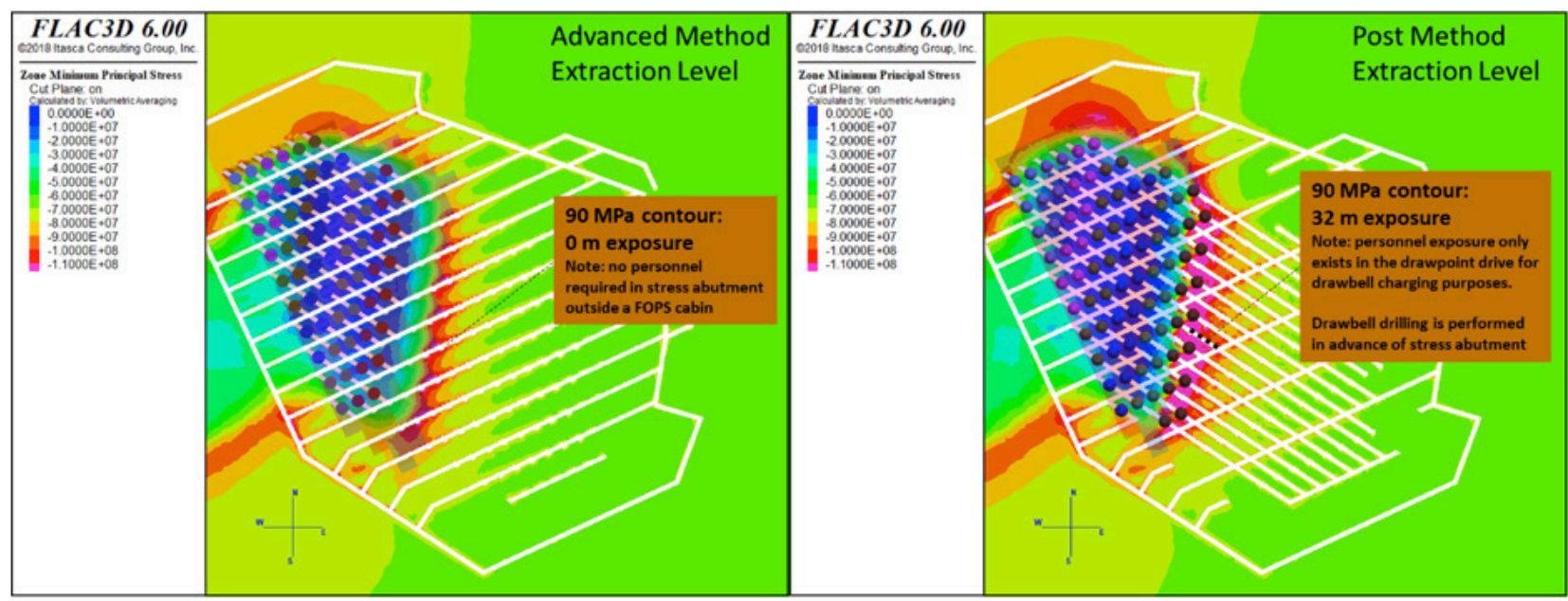

Figure 10 Stress abutments within the extraction level for both methods during undercutting 
Table 3 summarises the comparison of spatial extents in the stress abutment per drive unit for both the post and advanced methods where personnel are outside the protection of a FOPS cabin. For the level establishment phase, the post undercutting method generates almost 19\% more exposure than advance undercutting due to the amount of development required at this stage of a panel cave. However, during the cave establishment phase or undercutting, the advance method generates approximately $70 \%$ more linear exposure to abutment stresses than post undercutting, this is mainly explained by the localisation of high stresses on the undercut and apex levels. Similar findings have been identified in El Teniente mine (Pardo \& Rojas 2016).

Table 3 Summary of stress abutment spatial extents per drive where personnel are not protected by a FOPS cabin

\begin{tabular}{|c|c|c|c|}
\hline Phase & Level & Advanced & Post \\
\hline \multirow{3}{*}{ Level establishment } & Adv UC Apex & $62 \mathrm{~m}$ & - \\
\cline { 2 - 4 } & $\begin{array}{c}\text { UC (essentially the same for } \\
\text { both methods) }\end{array}$ & $97 \mathrm{~m}$ & $97 \mathrm{~m}$ \\
\cline { 2 - 4 } & Ext & $126 \mathrm{~m}$ & $241 \mathrm{~m}$ \\
\cline { 2 - 4 } & Totals & $285 \mathrm{~m}$ & $338 \mathrm{~m}$ \\
\hline \multirow{3}{*}{ Undercutting } & Apex & $29 \mathrm{~m}$ & - \\
\cline { 2 - 4 } & UC & $43 \mathrm{~m}$ & $10 \mathrm{~m}$ \\
\cline { 2 - 4 } & Ext & $72 \mathrm{~m}$ & $32 \mathrm{~m}$ \\
\cline { 2 - 4 } & Totals & $42 \mathrm{~m}$ \\
\hline
\end{tabular}

\section{$5 \quad$ Risk assessment}

In order to assess the safety of the personnel working in the undercut and extraction levels during undercutting, a quantification of the risk of personnel being exposed to a potentially damaging seismic event was required. This quantitative method, rather than more traditional semi-quantitative risk assessments, was used in order to remove as much human bias as possible and focus on the data available to make the decision.

\subsection{Personnel exposure}

The first part of the process was to assess the exposure time of personnel working in the stress abutment areas. This assessment focussed on the tasks undertaken by personnel working in the stress abutment areas outside the protection of engineered FOPS cabins. During these tasks, the installed ground support provides a critical control against the potential for rockfalls and this control has the potential to fail during a damaging seismic event. Refer to section 5.2, which details the specifications of the ground support critical control. A review of the activities involved in each of the undercutting strategies was conducted in order to assess both the time taken under "normal" conditions and the time taken when the activity is conducted on a "best case" and "worst case" basis. The data is represented as man hours per drawbell for each activity. This exposure is summarised in Table 4. 
Table 4 Summary of exposure hours for activities where personnel are not protected by a FOPS cabin in the stress abutment zones

\begin{tabular}{|c|c|c|c|}
\hline $\begin{array}{c}\text { Activity in stress abutment where } \\
\text { personnel are not protected by a } \\
\text { FOPS cabin }\end{array}$ & Category & $\begin{array}{c}\text { Option 1 advanced } \\
\text { undercut (hr/drawbell) }\end{array}$ & $\begin{array}{c}\text { Option 2 post undercut } \\
\text { (hr/drawbell) }\end{array}$ \\
\hline \multirow{2}{*}{$\begin{array}{c}\text { Long-hole Drawbell Prepping and } \\
\text { Charging }\end{array}$} & Mean & 0 & 21 \\
\cline { 2 - 4 } & $90 \%$ Low & 0 & 20 \\
\cline { 2 - 4 } & $90 \%$ High & 0 & 42 \\
\hline \multirow{2}{*}{$\begin{array}{c}\text { Long-hole Undercut prep and } \\
\text { charge }\end{array}$} & Mean & 40 & 80 \\
\cline { 2 - 4 } & $90 \%$ Low & 30 & 70 \\
\cline { 2 - 4 } & $90 \%$ High & 80 & 120 \\
\hline \multirow{2}{*}{$\begin{array}{c}\text { Long-hole Undercut re-work } \\
\text { Long-hole Drawbell re-work }\end{array}$} & Mean & 1 & 1 \\
\cline { 2 - 4 } & $90 \%$ Low & 0.5 & 0.5 \\
\cline { 2 - 4 } & $90 \%$ High & 1.5 & 1.5 \\
\cline { 2 - 4 } & $90 \%$ Low & $1.00 \mathrm{E}-06$ & $1.00 \mathrm{E}-06$ \\
\cline { 2 - 4 } & $90 \%$ High & 0 & 1 \\
\hline \multirow{2}{*}{$\begin{array}{c}\text { Survey and Inspection } \\
\end{array}$} & Mean & 2 & 2 \\
\cline { 2 - 4 } & $90 \%$ Low & 1.5 & 1.5 \\
\cline { 2 - 4 } & $90 \%$ High & 2.5 & 2.5 \\
\hline
\end{tabular}

\subsection{Probability of an adverse event}

In order to estimate the likelihood of having a damaging seismic event, the historical seismic catalogue in the Cadia province was used including data drawn from the Cadia East and Ridgeway Deeps (RWD) operations. Note, Ridgeway Deeps was an advanced undercut block cave located $5 \mathrm{~km}$ to the North of the Cadia East operation at a depth of approx. 1,100 m.

The calculations were based on the following process:

- A ML 2.0 event within $25 \mathrm{~m}$ of an excavation was chosen as a representative event magnitude and distance that has the potential to cause a ground support breach;

- The annualised seismic hazard was calculated for the four selected Newcrest case studies (RWD - Advanced, CE PC1 - Post, CE PC2 - Post and CE PC2 Advanced) for the entire timeframe that the undercutting strategy was taking place;

- The number of total drawbells was divided by the number of construction years to determine drawbells per year;

- The annualised seismic hazard values for each operation were then divided by the annualised number of drawbells;

- The estimated failure length was included to show differences in the likely damage zone, with an advanced undercut identified as having a spatially larger fault slip potential due to the larger active volume.

Table 5 shows the historical seismic hazard assessment for the four block caving operations established in the Cadia province. The assessment shows that the seismic hazard is higher for the advanced undercuts previously established than for the post undercuts. 
Table 5 Historical seismic hazard assessment

\begin{tabular}{|c|c|c|c|c|c|c|}
\hline UC strategy & $\begin{array}{c}\text { Start of } \\
\text { undercutting }\end{array}$ & $\begin{array}{c}\text { End of } \\
\text { undercutting }\end{array}$ & $\begin{array}{c}\text { Months of } \\
\text { undercutting }\end{array}$ & $\begin{array}{c}\text { Total } \\
\text { drawbells }\end{array}$ & $\begin{array}{c}\text { Drawbells } \\
\text { per year }\end{array}$ & $\begin{array}{c}\text { "Critical Event" } \\
\text { Chance of a ML }>2.0 \\
\text { seismic event within } \\
25 \text { m of the undercut } \\
\text { of extraction levels per } \\
\text { drawbell }\end{array}$ \\
\hline PC1 Post & Nov 2011 & Apr 2014 & 29 & 114 & 47 & $0.28 \%$ \\
\hline PC2 Post & Feb 2014 & Feb 2015 & 12 & 88 & 88 & $0.44 \%$ \\
\hline $\begin{array}{c}\text { PC2 } \\
\text { Advanced }\end{array}$ & Aug 2015 & Dec 2016 & 16 & 77 & 58 & \\
\hline $\begin{array}{c}\text { RWD } \\
\text { Advanced }\end{array}$ & May 2008 & Nov 2010 & 30 & 130 & 52 & $0.67 \%$ \\
\hline
\end{tabular}

Given the conditions likely to be encountered in CE PC2-3 it was considered that the two estimates for CE PC2 (one as an advanced and one as a post) were the most representative of the CE PC2-3 conditions. The values for CE PC1 and RWD provide correlating evidence that the risk for a post undercut is lower than an advanced undercut in Cadia's rock mass. The values used in the risk calculation are shown in Table 6. For this table the upper and lower estimate ranges were:

- $\quad$ For the Post Undercut option - using CE PC1 Post Undercut likelihood as the lower bound based and CE PC2 Advanced Undercut likelihood as the upper bound.

- For the Advanced Undercut option - using CE PC2 Post Undercut likelihood as the lower bound and RWD Advanced Undercut as the upper bound.

Table 6 Hazard assessment for risk assessment

\begin{tabular}{|c|c|c|c|}
\hline Root cause & Estimate name & $\begin{array}{c}\text { Option 1 advanced } \\
\text { undercut }\end{array}$ & $\begin{array}{c}\text { Option 2 post } \\
\text { undercut }\end{array}$ \\
\hline \multirow{2}{*}{$\begin{array}{c}\text { Seismic event occurrence in } \\
\text { the stress abutment area (per } \\
\text { drawbell) }\end{array}$} & Mean & $0.67 \%$ & $0.44 \%$ \\
\cline { 2 - 4 } & $90 \%$ Low & $0.44 \%$ & $0.28 \%$ \\
\hline \multirow{2}{*}{$\begin{array}{c}\text { Metres of failure in an event in the } \\
\text { stress abutment area }\end{array}$} & $90 \%$ High & $0.88 \%$ & $0.67 \%$ \\
\cline { 2 - 4 } & Mean & 2 & 2 \\
\cline { 2 - 4 } & $90 \%$ Low & 1 & 1 \\
\hline
\end{tabular}

\subsection{Risk quantification}

An assessment of the risk was undertaken by a group of Newcrest employees operationally experienced in undercutting and drawbell establishment. During the Risk Assessment the fault tree presented in Figure 11 was developed to describe the chance of a "Critical Event" which is of a rockburst event in the presence of people working in the stress abutments whilst outside of the protection of a FOPs cabin. 


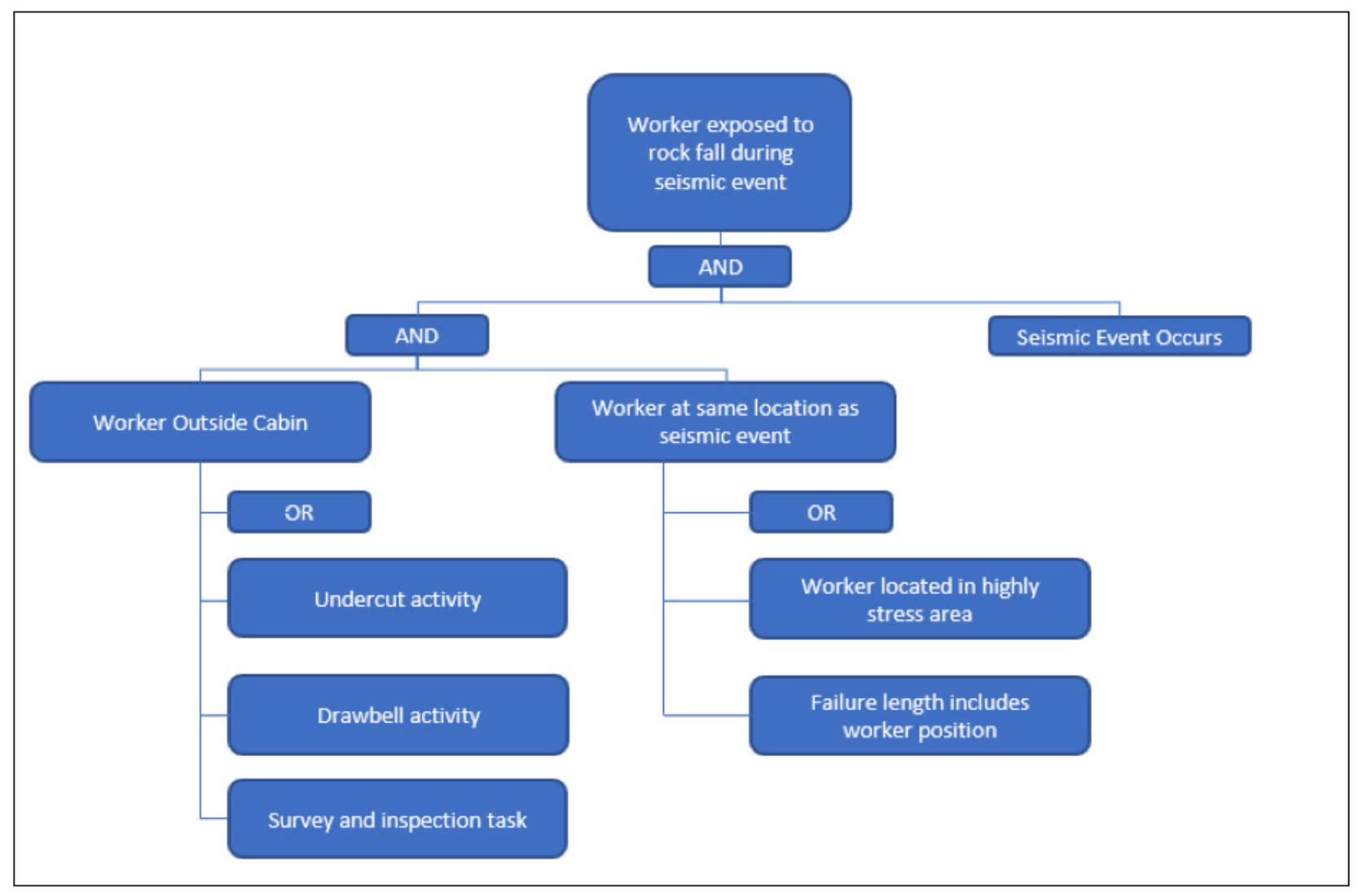

\section{Figure 11 Fault tree for a critical event}

Table 5 and Table 6 above have been used to populate the Fault Tree and subsequently run a simulation. The major differences apparent based on the numerical analysis were that during post undercutting the undercut level is not considered exposed to high stress conditions and that in the Advanced Undercut the extraction level is not considered exposed based on the stress abutment being located ahead of the drawpoint and drawbell development.

Based on these inputs and the fault tree logic, the following estimate and comparison of a large (>2.0ML) event in the proximity of personnel working is shown in Figure 12.

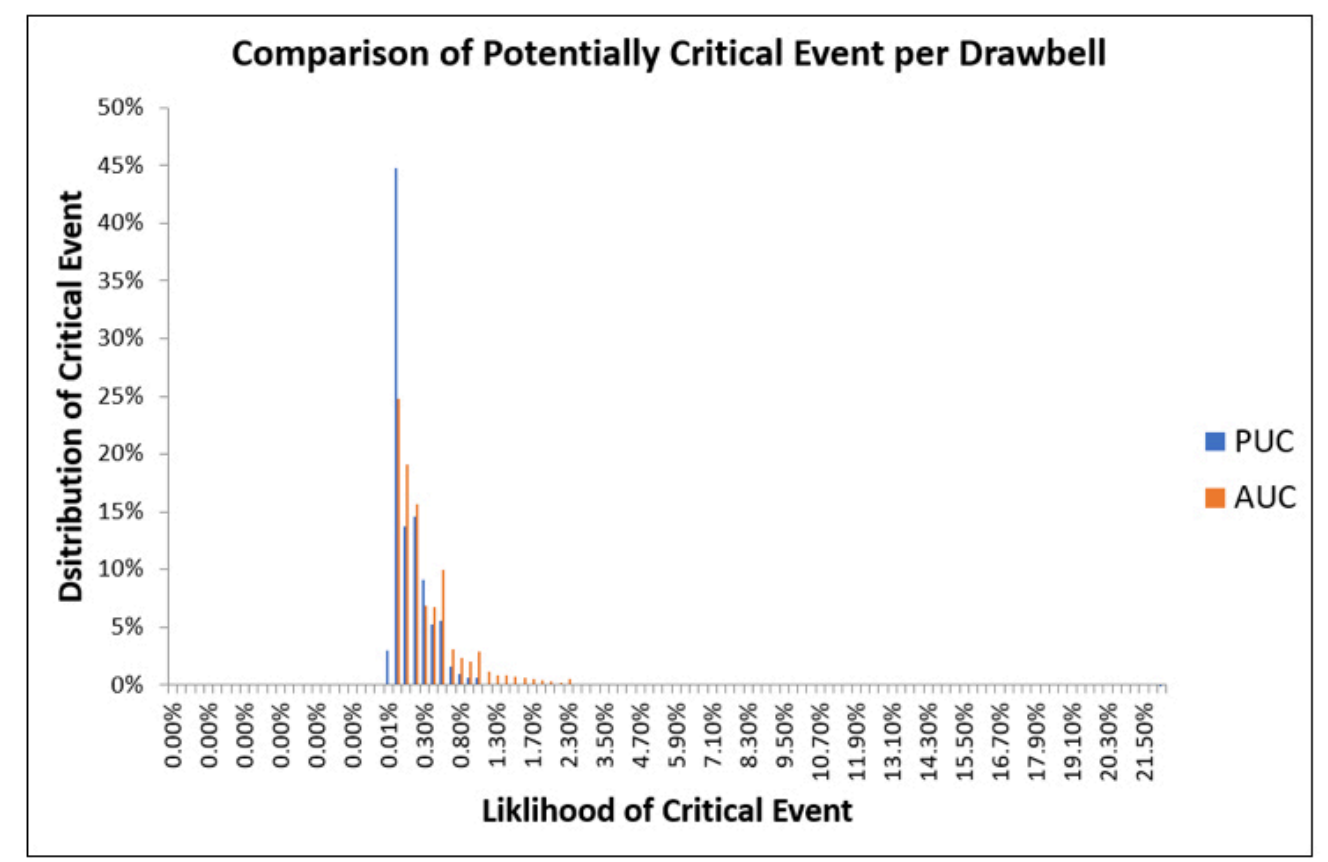

Figure 12 Quantitative comparison of the likelihood of a rockburst event in the presence of people prior to application of critical controls 
From Figure 12, the likelihood of the occurrence of the critical event is drawn from the following criteria:

- Both methods have a low probability of having a large event at the same time as a person is exposed;

- This assessment does not include the application of critical controls (summarised in the next section);

- These figures should be used only for comparison purposes for the evaluation of the undercutting process options; and

Notwithstanding the low probability, the assessment also shows that if conditions are unfavourable, the Advanced Undercut will, most likely, produce a worse outcome making this option less favourable.

\section{$6 \quad$ Risk controls}

The approach undertaken for Newcrest to reduce the seismic risk is based on the following risk controls.

\subsection{Dynamic ground support}

The likelihood presented above has been assessed without using a critical control to protect personnel. For both methods, the following critical control must be implemented to reduce the risk of an unwanted seismic event injuring a person further:

- The final dynamic ground support for the different levels must be completed prior to the area being subjected to the induced stress abutment from undercutting and must be designed to withstand the most credible largest seismic event.

The introduction of dynamic ground support as a critical control then reduces the risk of a critical event in both cases as it mitigates the risk to personnel to almost zero.

\subsection{Hydraulic fracturing}

Hydraulic fracturing at Cadia has been observed to reduce the frequency and magnitude of large seismic events. It has been postulated that the process of implementing new fractures into the rock mass reduces the size of the naturally occurring rock bridges, subsequently reducing the potential for the rock bridges to store energy (Glen et al 2019). This positive effect of seismicity has also been observed at other caving operations such as El Teniente (Rojas \& Balboa 2017).

For the PC2-3 project, it is intended to use hydraulic fracturing to implement fractures in the orebody to enhance cavability, but also to systematically fracture the rock mass housing the production levels and infrastructure development to reduce the seismic hazard. Because a transient stress abutment is generated through the extraction level pillars during undercutting, it is intended to implement fractures at $4 \mathrm{~m}$ vertical spacings through the major apex pillars to $30 \mathrm{~m}$ below the extraction level. This strategy is expected to reduce the likelihood of damaging seismic events in the extraction level where the undercutting related stress abutment is located.

\section{Conclusions}

This paper has outlined the process used in the Cadia East PC2-3 Expansion Feasibility Study to assess the personnel exposure to an unwanted seismic event during undercutting for both an advanced undercut and a post undercut and to subsequently select the undercutting method which has the least personnel exposure.

The result of the assessment demonstrated that the overall personnel exposure to an unwanted event during cave establishment is less for the high-lift post undercut method within the CE PC2-3 geotechnical 
setting. Newcrest's experience has also shown that high-lift post undercutting combined with intensive pre-conditioning provides advantages in operational flexibility, better fragmentation during the cave initiation phase, less interaction between the cave establishment and production crews and produces a better business outcome.

In conclusion, the selected undercutting method for the CE PC2-3 extension was a high-lift post undercut. In addition, Newcrest has also implemented the following controls to further enhance the safety and productivity of the CE PC2-3 project:

- Newcrest's design and operational caving rules for block and panel caving including seismic management planning, intensive preconditioning (combining hydrofracturing and confined blasting techniques) and dynamic ground support among others (Cuello \& Newcombe 2018; Flores-Gonzalez 2019); and

- Working with industry partners to develop remote and autonomous equipment to further remove personnel from areas of high risk.

\section{Acknowledgement}

The authors acknowledge the support of Newcrest Mining for allowing the publication of this paper, and the following personnel that supplied data, information and insights into this work; namely, Chris Chester, David Cuello, Stephen Duffield, James Lett, lan Austen, Stuart Martin and German Flores.

\section{References}

Cuello, D \& Newcombe, G 2018, 'Key geotechnical knowledge and practical mine planning guidelines in deep, high-stress, hard rock conditions for block and panel cave mining', in Y Potvin \& J Jakubec (eds), Proceedings of the Fourth International Symposium on Block and Sublevel Caving, Australian Centre for Geomechanics, Perth, pp. 17-36.

Flores-Gonzalez, G 2019, 'Major hazards associated with cave mining: are they manageable?', in J Wesseloo (ed.), Proceedings of the First International Conference on Mining Geomechanical Risk, Australian Centre for Geomechanics, Perth, pp. 31-46.

Glen, D 2019, 'A review of hydraulic fracturing the Southern Seismic Zone', Internal Technical Memorandum, 12 June 2019

Hoek, E., \& Diederichs, MS 2006, 'Empirical Estimation of Rock Mass Modulus', Int. J. Rock Mech. Min. Sci., vol.43, pp. 203215.

Itasca Australia Pty Ltd 2017a, 'Numerical Assessment of Life of Mine Subsidence', Report Ref: 17005_4.

Itasca Consulting Group Inc. 2017b, 'FLAC3D — Fast Lagrangian Analysis of Continua in Three-Dimensions', Ver. 6.0. Minneapolis: Itasca.

Kaiser, P. 2019, 'From common to best practices in underground rock engineering', 8th Mueller lecture presented at the 14th ISRM Congress, Brazil, CRC Press, pp. 141-182 in e-book.

Lee, M 2012, Cadia East - 'Review of Rock Stress Measurements', AMC Consultants Pty Ltd report to Newcrest Mining Limited. AMC 111153: February 2012.

Lett, J, Brunton, I, Capes, G, Jäger, A, Mobilio, B, Rachocki, J, Sharrock, G \& Secheny, M 2016, 'Undercutting to surface breakthrough - Cadia East panel cave (stage 1)', in C Carr \& G Chitombo (eds), Proceedings of the Seventh International Conference and Exhibition on Mass Mining, The Australasian Institute of Mining and Metallurgy, Melbourne, pp. 65-81.

Lorig, L \& Pierce, M 2000, 'Methodology and Guidelines for Numerical Modelling of Undercut and Extraction Level Behaviour in Caving Mines', Report to International Caving Study. Minneapolis: Itasca Consulting Group. pp. 6.1-6.40.

Noma Consulting 2018, 'Cadia East Panel Cave Life of Mine Caving Assessment', Report: CAD4-NEW-NOM-GEO-RPT-0001-A.

Orrego, C 2018, Internal Technical Memorandum - 'PC 2-3 Crusher Chamber Location Assessment'. [05 October 2018]. 
Pardo, C \& Rojas, E 2016, 'Selection of exploitation method based on the experience of hydraulic fracture techniques at El Teniente Mine', in C Carr \& G Chitombo (eds), Proceedings of MassMin 2016, The Australasian Institute of Mining and Metallurgy, Melbourne.

Rojas, E \& Balboa, S 2017, 'Management of seismic hazard in high stress condition, El Teniente mine', in JA Vallejos (ed.), Proceedings of the 9th International Symposium on Rockbursts and Seismicity in Mines, University of Chile, Santiago, pp. 264-273. 